Gut, 1977, 18, 37-44

\title{
Consequences of partial and subtotal colectomy in the rat
}

\author{
P. C. MASESA ${ }^{1}$ AND J. M. FORRESTER \\ From the Physiology Department, Edinburgh University, Scotland
}

SUMMARY Rats were subjected to right hemicolectomy (including removal of the caecum), left hemicolectomy or subtotal colectomy. Body weight resumed and maintained a rate of increase very similar to that in control rats. After hemicolectomy, food intake showed no change. Faecal weight increased by about one-third after right hemicolectomy, but did not increase after left hemicolectomy. After right hemicolectomy, the remaining - that is, downstream-portion of the colon showed increase in weight, and so did the (upstream) small intestine, in which the increase involved all three-thirds of its length and was predominantly mucosal. No such changes in the remaining colon or in small intestine were found after left hemicolectomy. After subtotal hemicolectomy, rats ate $30-40 \%$ more food than control rats, and faecal weight increased $60 \%$ at three months after operation. Study of energy intake and output indicated diminished absorption. All three-thirds of the small intestine showed increase in weight, predominantly mucosal in the upper two-thirds and predominantly seromuscular in the lowest third; villi were taller at all levels. Evidence suggests that the increase in food intake is not due to cessation of coprophagy, and that the small intestine changes are not due solely to increased food intake and occur when the colon is bypassed but not removed.

The effects of partial resection of the small intestine in rats have been extensively studied (for references see Dowling, 1974). The effects of partial or subtotal resection of the colon have been less fully examined. It is known that after subtotal resection in rats the distal ileum shows taller villi, but little change in the number of enterocytes along unit length of the villus margin; and water absorption measured per unit length of ileum increases (Wright et al., 1969b). Similar changes were shown in man (Wright et al., 1969a). The present study explores further the consequences of partial and subtotal colectomy in rats.

A brief communication of some of these results has been given to the Physiological Society (Masesa, 1976).

\section{Methods}

Operations were performed on male Wistar rats between 2 and 3 months old, reared initially free of specific pathogens. At 2 months old these rats attain

'Present address: University of Dar es Salaam, P.O. Box 20693, Dar es Salaam, Tanzania.

Received for publication 3 August 1976 a weight of about $200 \mathrm{~g}$, and their food intake has reached an adult plateau although body weight continues to rise (Forrester, 1972). They were paired according to body weight and allotted to operative procedures by conventional random methods. Right hemicolectomy removed segment A (Fig. 1); it comprised removal of the caecum, about $0.5 \mathrm{~cm}$ of terminal ileum, and about the proximal tenth of the total length of the colon. This is the 'right colectomy' or 'partial colectomy' of Lambert (1965). Left hemicolectomy comprised removal of about a fifth of the length of the whole colon (segment B in Fig. 1) and the anastomosis lay about $1.5 \mathrm{~cm}$ above the anus. Subtotal colectomy comprised removal of both portions and of the intervening segment (C in Fig. 1) of colon; it appears synonymous with the 'total colectomy' of Wright et al. (1969b) and with the 'total colectomy' of Lambert (1965), and terminal ileum was anastomosed to rectum. In a separate group of rats the colon was left in place but bypassed by anastomosing terminal ileum to the side of distal colon at the same site as in subtotal colectomy. Control animals underwent simple transection of the terminal ileum with anastomosis. Certain animals underwent no operation and are termed 'normal' in 


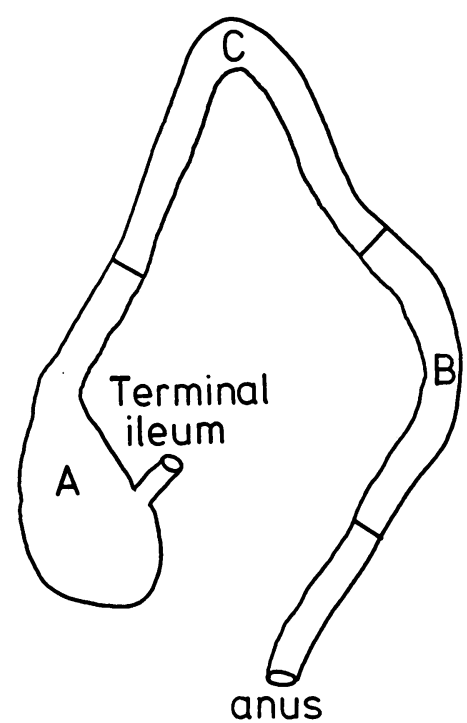

Fig. 1 Portions of rat colon removed at operation. See ext.

this paper. Animals were killed as required by inhalation of chloroform in the early afternoon.

Weight of food intake is stated as dried to constant weight; food scattered was weighed and deducted. Stomach to anus transit time was measured by intragastric administration of $3 \mathrm{ml}$ barium sulphate suspension (Micropaque, Damancy) to unfasted animals in the evening and subsequent radiographic examination of faeces. Intermediate transit times were measured by similar administration to fasted animals in the morning and observation by image intensifier; this procedure is not precisely comparable with that used for stomach to anus transit time, but was followed as the image intensifier was not accessible overnight. Fasting avoided overdistension of the stomach when the barium was given.

Intestinal wet and dry weights were measured by conventional methods, and mucosa was separated from seromuscular coat by scraping (Gleeson et al., 1972). Fixation of histological preparations was started with $10 \%$ acqueous formalin in vivo under anaesthesia. Mean villus height was assessed from 30 well-oriented tallest villi in six serial transverse sections $10 \mu \mathrm{m}$ thick stained with haematoxylin and eosin. Enterocyte density was measured in the same selected villi by counting over $150 \mu \mathrm{m}$ of mid-villus edge.

Results (unless stated otherwise) are given as mean \pm standard error of the mean, and comparisons were made by paired $t$ test. Groups of rats were generally eight in number and never less than six.

\section{Results}

EFFECTS OF RIGHT AND LEFT HEMICOLECTOMY Body weight

After about a week of recovery from either left or right hemicolectomy, rats reverted to steady weight gain and paralleled the progress of both unoperated and control rats (Figs. 2 and 3), though not showing 'catch-up' growth. Figure 3 shows strikingly little disturbance by the operation in the progress of both control rats and rats undergoing left hemicolectomy. These rats were younger and lighter than the rats used in right hemicolectomy, and therefore possibly more resilient; the wet weight of tissue removed in the two procedures does not differ by so much as $1 \mathrm{~g}$ and so cannot explain the difference.

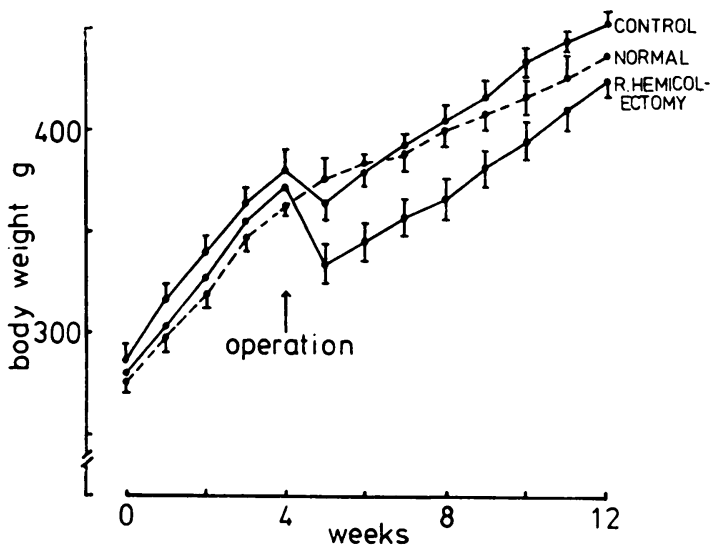

Fig. 2 Body weight of normal and control rats and rats after right hemicolectomy.

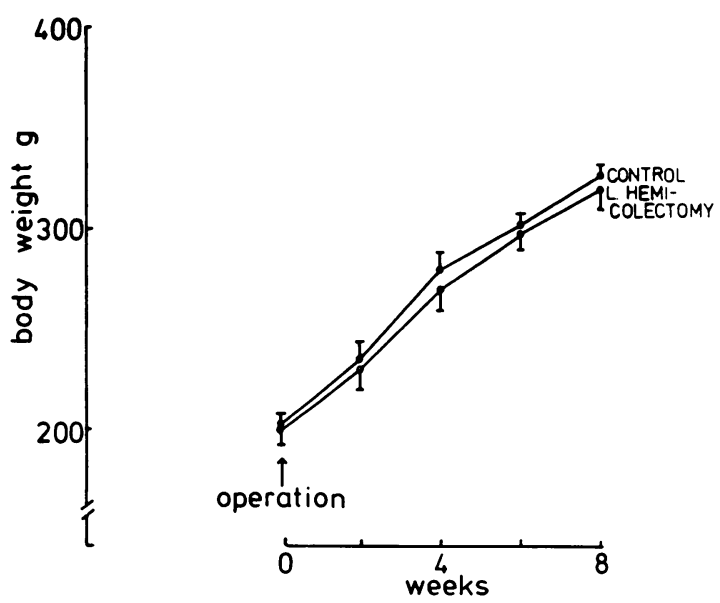

Fig. 3 Body weight of control rats and rats after left hemicolectomy. 
Food intake and faecal output

At two weeks and again seven weeks after operation, food intake of operated and control rats showed no significant difference; indeed, the mean intake of rats seven weeks after right hemicolectomy was slightly less than that of control rats. The data are available elsewhere (Masesa, 1975). After right hemicolectomy, faeces were semi-fluid for some two to three weeks and thereafter less well-formed than normal. Dry weight of faeces excreted daily was unchanged after left hemicolectomy, but after right hemicolectomy it increased by $37 \%$ when measured three months later, and the loss of weight on drying also rose, by about $12 \%$.

\section{Intestinal transit}

This was compared in six normal rats and in six rats three months after right hemicolectomy. Table 1 shows that the head of the barium load reached the end of the small intestine more quickly after right hemicolectomy, but then cleared from the stomach and small intestine more slowly.

\section{Colonic remnant after right or left hemicolectomy}

The weight of colon removed at operation was measured and also the weight remaining at killing three months later. The caecum was not included in either measurement. In this way it was possible to detect compensatory growth of the remnant by comparison with control rats in which operation and killing were done at the same times as in experimental rats; thus growth of the normal colon over the relevant period of a rat's life was taken into account. After right hemicolectomy obvious compensatory growth of the distal colon occurs (Fig. 4), the remnant colon actually weighing about $37 \%$ more than the entire control colon $(P<0.02)$. Figure 4 shows wet weight; dry weight gave very similar

Table 1 Progress of barium load inserted by gastric intubation in six normal rats and in six rats three months after right hemicolectomy

\begin{tabular}{llll}
\hline & $\begin{array}{l}\text { Normal } \\
(\mathrm{min})\end{array}$ & $\begin{array}{l}\text { R. hemi- } \\
\text { colectomy } \\
(\mathrm{min})\end{array}$ & P \\
\hline $\begin{array}{l}\text { To reach anastomosis or } \\
\text { caecum }\end{array}$ & $220(175-295)$ & $175(145-205)$ & $<0.01$ \\
$\begin{array}{l}\text { Till major portion of } \\
\text { barium had entered } \\
\text { colonic remnant or } \\
\text { caecum }\end{array}$ & $273(265-290)$ & $345(310-400)$ & $<0.01$ \\
$\begin{array}{l}\text { Small intestine empty of } \\
\text { barium }\end{array}$ & $430(385-450)$ & $493(450-510)$ & $<0.01$ \\
$\begin{array}{l}\text { Stomach empty of barium } \\
\text { (185 }\end{array}$ & $185(145-265)$ & $330(205-475)$ & $<0.005$ \\
\hline
\end{tabular}

Ranges are stated in parentheses. ratios. The ratio of mucosal weight to seromuscular weight $(1 \cdot 45 \pm 0 \cdot 1)$ was not significantly greater than in control animals $(1.27 \pm 0.1)$ indicating that mucosa and seromuscular coat were both concerned in the increase. But after left hemicolectomy (Fig. 4) there was no evidence of compensatory growth in the proximal colon. It is possible that some mucosal growth had occurred at the expense of the seromuscular coat, as the ratio of mucosal weight to seromuscular weight had changed from $1.32 \pm 0.12$ (control) to $1.65 \pm 0.16$, but this change did not reach significance. There was no significant change in the weight of the caecum after left hemicolectomy, though its mean fresh weight was $6 \%$ less than in control animals.

\section{Changes in small intestine}

Weight changes in the small intestine were not found after left hemicolectomy. But in rats killed three months after right hemicolectomy there was a $23 \%$ increase in the weight of the small intestine ( $\mathrm{P}<$ 0.005 ), whether measured wet or dry, and this was examined in more detail. Weights of the small intestine divided into thirds indicated that the increase involved all thirds, but especially the lowest third (Fig. 5). Separation of mucosal and seromuscular components showed that the mucosal contribution predominated (Fig. 6). But measurement of villus height three months after operation (Fig. 7)

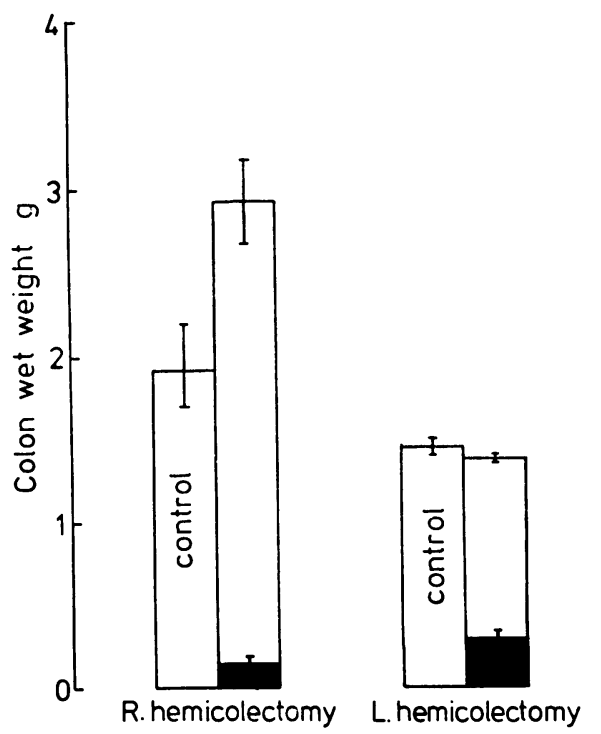

Fig. 4 Colon weight in control rats, weight removed at hemicolectomy (filled segment of right columns) and weight found at killing three months after hemicolectomy (open segment of right columns) Note that caecum is not included. 


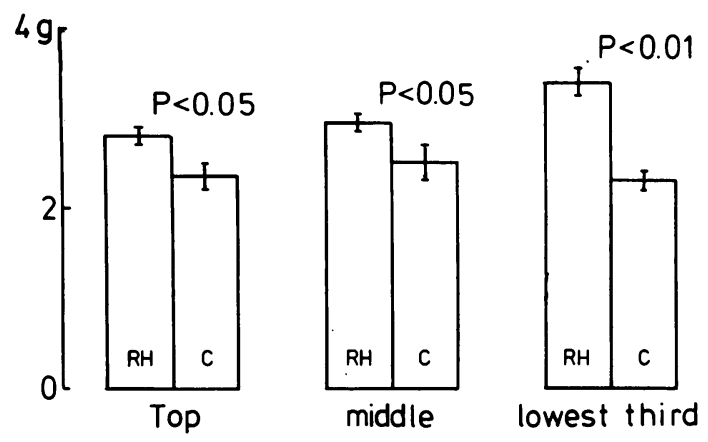

Fig. 5 Wet weight of small intestine in control rats $(C)$ and in rats three months after right hemicolectomy $(R H)$.
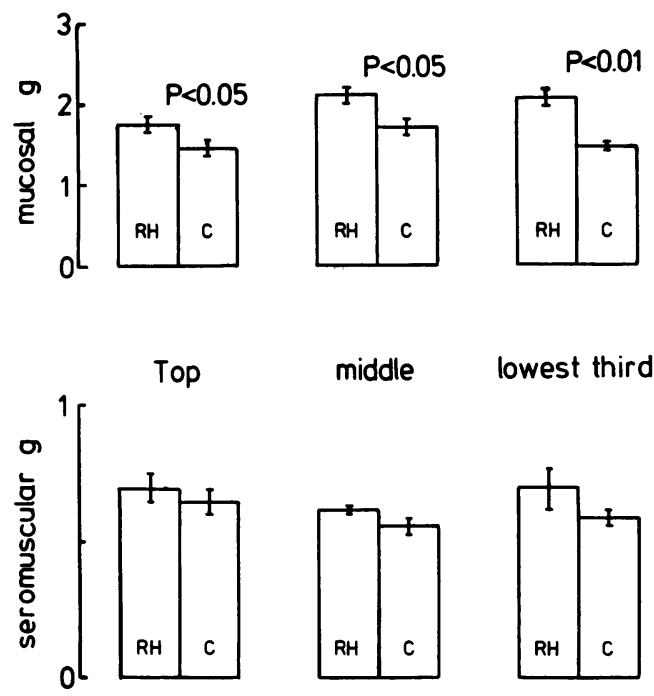

middle
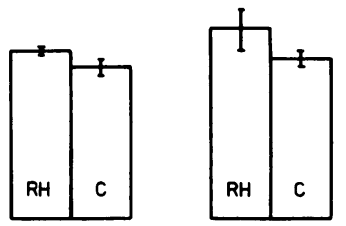

Fig. 6 Wet weight of small intestine three months after right hemicolectomy, divided into components.

failed to demonstrate any change, except in the most proximal segment, where an increase in height in the hemicolectomised animals was significant $(P<0.05)$. However, at all levels below the most proximal three, enterocyte density (Fig. 8) showed a slight (6-7\%) but significant $(\mathrm{P}<0.01)$ increase. Changes in the overall length of the small intestine were sought, but not found; the length removed at hemicolectomy was about $0.5 \mathrm{~cm}$ only.

\section{EFFECT OF SUBTOTAL COLECTOMY}

Body weight and blood

About $90 \%$ of rats survived the operation and the first three post-operative days; very few died later.

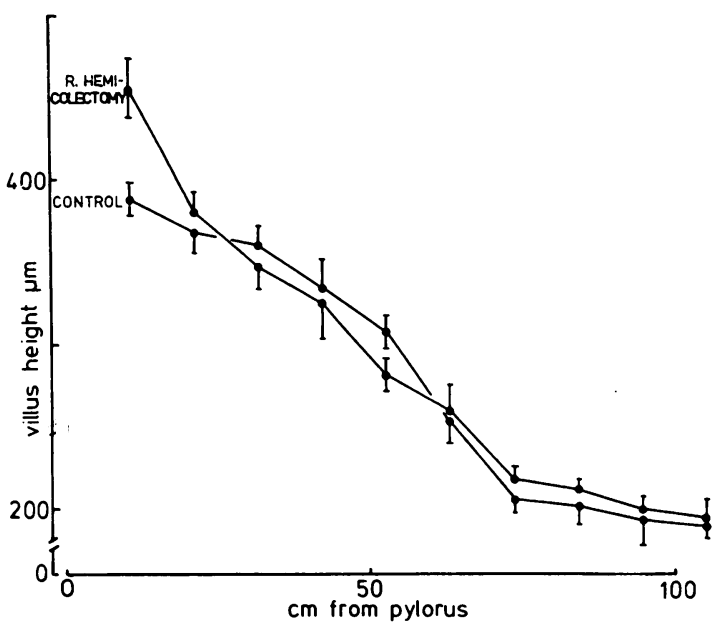

Fig. 7 Villus height three months after right hemicolectomy.

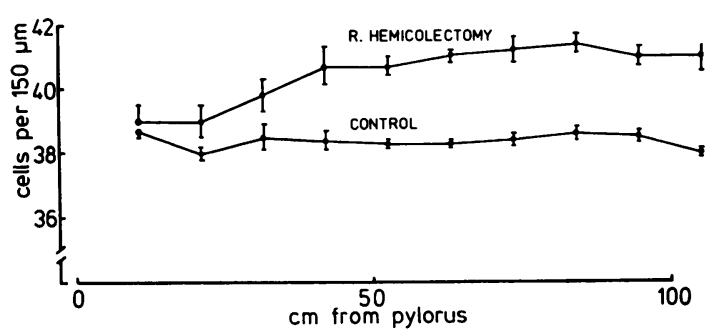

Fig. 8 Enterocyte density three months after right hemicolectomy.

Like hemicolectomised rats, after subtotal colectomy rats resumed steady weight gain (Fig. 9) but did not reach the weights attained by normal or by control rats. Tail blood taken between four and 12 weeks after operation showed no significant difference from that of control rats in WBC count, $\mathrm{MCV}$ or $\mathrm{Hb}$ content; in particular, at 12 weeks $\mathrm{Hb}$ content was $15 \pm 0.4 \mathrm{~g} / \mathrm{dl}$ in colectomised rats and $15.6 \pm 0.3 \mathrm{~g} / \mathrm{dl}$ in control rats. The rat diet contained no added $B$ vitamins.

\section{Food intake and faecal output}

By two weeks after operation, and still at three and at four months after operation, rats were eating $30-40 \%$ more food than control rats $(P<0.01)$. The increased intake was consistent throughout the night and not confined to early or late hours. Faeces remained unformed and semi-solid throughout the period studied (up to four months), and were very watery for the initial three to four weeks after operation. Measurements of faecal dry weight at three 


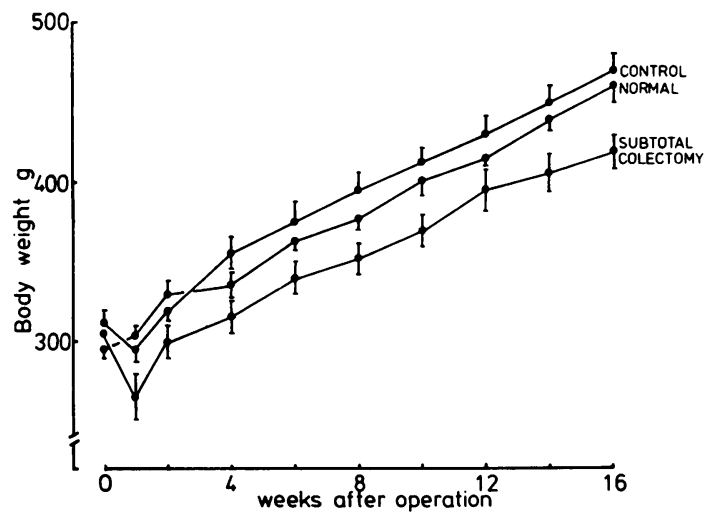

Fig. 9 Body weight of normal and control rats and rats after subtotal colectomy.

months after operation showed a $60 \%(\mathrm{P}<0.001)$ increase over control values, which is rather greater than the percentage increase in food intake.

The suspicion of faulty absorption thus created was strengthened on comparing intake and output of combustible energy by bomb calorimetry (Table 2 ), although this method neglects possible changes in bacterial metabolism of components of colon contents. Three months after operation, rats were excreting in faeces $57 \%$ more energy than control rats $(P<0.01)$, though only consuming (in this particular group of rats) $37 \%$ more. But the extra excretion only amounted to some $43 \mathrm{~kJ}$ per day; the rats were consuming an extra $116 \mathrm{~kJ}$ per day.

\section{Intestinal transit}

In these rats, stomach-to-anus transit time was studied, and screening to detect intermediate progress was not employed. Rats served as their own controls and the emergence of barium in faeces was observed during 14 hours after insertion by gastric intubation, both before and after (three weeks and

Table 2 Combustible energy intake and absorption

\begin{tabular}{|c|c|c|c|}
\hline & $\begin{array}{l}\text { Subtotal } \\
\text { colectomy }\end{array}$ & $\begin{array}{l}\text { Control } \\
\text { operation }\end{array}$ & $\mathbf{P}$ \\
\hline $\begin{array}{l}\text { Food intake: dry weight } \\
\text { Energy content of food } \\
\text { per g dry weight }\end{array}$ & $\begin{array}{r}24 \cdot 3 \mathrm{~g} \\
17 \cdot 8\end{array}$ & $17 \cdot 8 \mathrm{~g}$ & $<0.001$ \\
\hline $\begin{array}{l}\text { Energy intake } \\
\text { Dry weight of faeces } \\
\text { Energy output in faeces } \\
\text { Energy absorbed } \\
\text { Absorption as } \% \text { of intake }\end{array}$ & $\begin{array}{c}433 \mathrm{~kJ} \\
7 \cdot 7 \mathrm{~g} \\
118 \mathrm{~kJ} \\
315 \mathrm{~kJ} \\
73 \%\end{array}$ & $\begin{array}{r}317 \mathbf{k J} \\
4 \cdot 8 \mathrm{~g} \\
75 \mathrm{~kJ} \\
237 \mathrm{~kJ} \\
75 \%\end{array}$ & $\begin{array}{l}<0.001 \\
<0.005\end{array}$ \\
\hline
\end{tabular}

Mean values per rat per day three months after operation. three months) operation. Normal rats were also studied. Before subtotal colectomy, barium first appeared in faeces six hours after insertion and was still present 14 hours after insertion. After colectomy, barium first appeared at three or four hours and was virtually all through by eight hours, dispersion being evidently much less.

\section{Effect upon small intestine}

In eight rats killed eight months after subtotal colectomy, the weight of the whole small intestine was $33 \pm 0.7 \%$ greater than in control animals (P $<0.01)$. In eight other rats killed four months after subtotal colectomy, the increase involved all of the small intestine, but predominantly the top and lowest thirds (Fig. 10). In the top third, the mucosal percentage increase was rather greater than the seromuscular increase, but in the lowest third the reverse was true, the seromuscular coat showing the greater percentage increase (Fig. 11). Unlike the villi after right hemicolectomy, the villi after subtotal colectomy were consistently a little taller at every level (Fig. 12), especially towards the top end and then abruptly in the terminal segment, a $10-12 \%$ difference $(\mathrm{P}<0.01)$ occurring at both these regions. Enterocyte density was a little $(7 \%)$ greater after subtotal colectomy at all levels of the small intestine $(P<0.01$ at all levels) (Fig. 13). Changes in overall length of the small intestine were sought, but not found.

\section{Effect of pair feeding}

In order to estimate the role of the increased food intake of the colectomised rat in producing their enlarged small intestine, a group of eight animals was pair fed for three weeks three months after subtotal colectomy, receiving daily only the food consumed by their control partners the previous day. Calculated allowance was made for food scatter. At the end of the three weeks, the colectomised animals had lost $4 \%$ of their body weight and the control animals had gained $3.5 \%$. Figure 14 shows that the marked changes of Fig. 10 had considerably dimin-
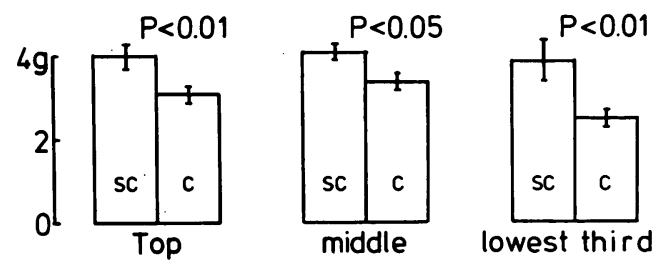

Fig. 10 Wet weight of small intestine in control rats $(C)$ and in rats four months after subtotal colectomy (SC). 


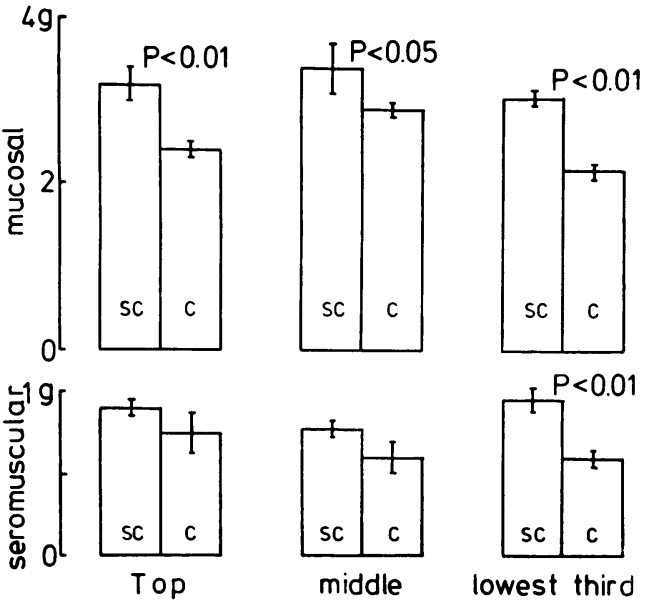

Fig. 11 Wet weight of small intestine four months after subtotal colectomy, divided into components.

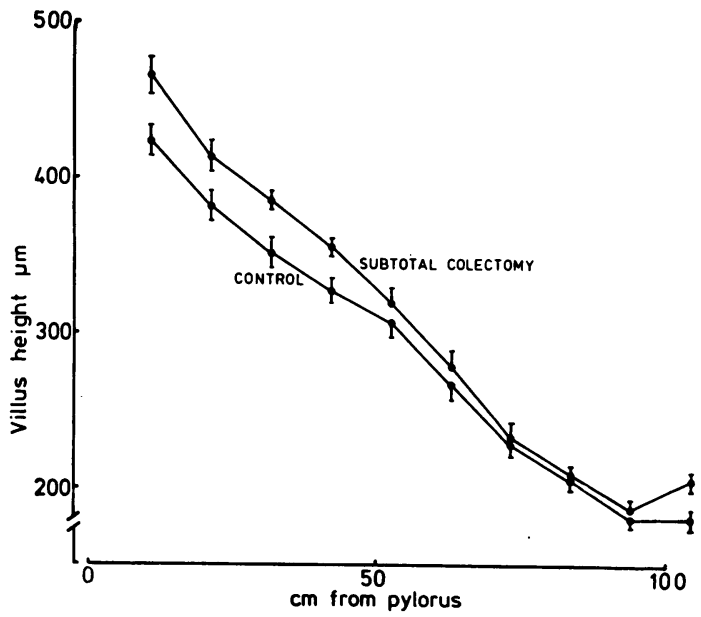

Fig. 12 Villus height three months after subtotal colectomy

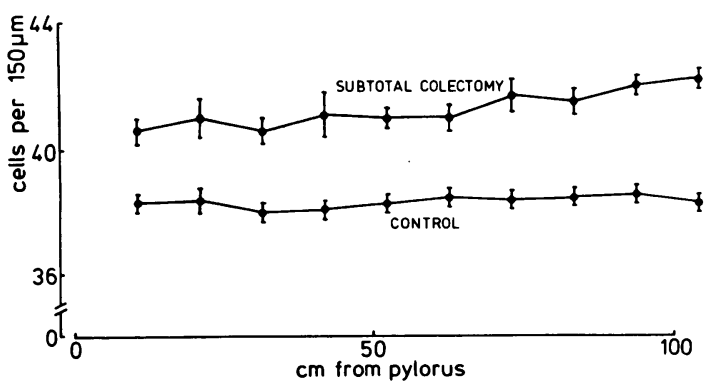

Fig. 13 Enterocyte density three months after subtotal colectomy.

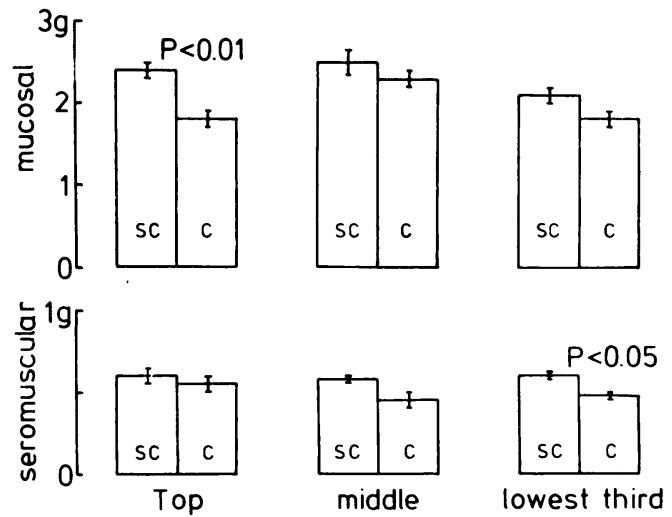

Fig. 14 Small intestinal weight at end of three weeks of pair feeding of control $(C)$ rats and rats after subtotal colectomy $(S C)$.

ished, especially in the seromuscular coat, but the mucosa of the top third was still prominently heavier in the colectomised rats, and the whole small intestine was still $17 \pm 0.4 \%$ heavier.

\section{Effect of colon bypass}

It seemed possible that the consequences of removing the colon might differ from those of bypassing it but leaving it in place. A group of eight rats were so treated and killed three months after operation. Their food intake was raised just like that of colectomised rats, no significant difference being found, and their body weight increased indistinguishably from that of colectomised rats. The total weights of the small intestine of bypass and colectomised rats were similar, and so were the weights of the mucosa and seromuscular coat for the three thirds. However, it is true that the mean weight of each component (mucosal and seromuscular) in each third was 1-10\% less after colon bypass than after subtotal colectomy, but the differences were not significant.

\section{Discussion}

INCREASED FOOD INTAKE AFTER SUBTOTAL COLECTOMY

It is striking that increased food intake is not seen in rats after partial resection of the small intestine (Dowling, 1968). After subtotal colectomy, deficient absorption appears a partial explanation. It seems anomalous that absorption should be impaired when the small intestine is actually larger than normal, but the role of the large intestine in digestion and absorption of 'unavailable carbohydrates' is established. However, absorption of these is unlikely to exceed $2.5 \%$ of the energy uptake in man (Southgate, 1973). 
It may be a little more extensive in the rat, but there is evidence that uptake of volatile fatty acids from the caecum of rats on a normal diet amounts only to about $5 \%$ of the daily energy intake (Yang et al., 1970); in normal rats volatile fatty acids are formed almost exclusively in the large intestine (Yang et al., 1969). Neither these observations nor the present results suggest a failure of absorption in colectomised rats sufficient to match the substantial increase in food intake.

It also seemed possible that after subtotal colectomy rats refrain from coprophagy because of the change in faecal composition and consistency, thus impairing absorption by losing the 'second time round', and possibly eating additional food instead of faeces. The occurrence of extensive coprophagy in normal fully fed rats is well known (Barnes et al., 1957) and is easily shown through the presence of formed faecal pellets in gastric contents; the unformed faeces of colectomised rats cannot be so easily discerned. But the discovery of free bile acids in their gastric contents (Masesa, 1975) excludes the possibility that there is no coprophagy at all in colectomised rats; free bile acids are found in rat small intestine only in the distal part (Dietschy, 1967).

Whether appetite increases in normal man after colectomy is hard to establish, since appetite is likely to be influenced both before and after operation by disorders requiring colectomy, measured food intakes vary greatly from one normal person to another (Edholm et al., 1955), and human appetite is greatly dependent on habit and custom. Increased intakes in some patients with coeliac or pancreatic disease, or after resection of the small bowel, have been described (Hall and Creamer, 1974).

\section{INTESTINAL TRANSIT}

After right hemicolectomy, prompt arrival of a little barium beyond the anastomosis but a slow subsequent build-up suggest that the anastomosis presents no mechanical obstruction, but propulsion through it is not as effective as through normal gut. This impression was strengthened at killing when the gut just $(1 \mathrm{~cm})$ above and below the anastomosis was invariably dilated and loaded with semi-solid contents, yet the anastomotic site showed no evidence of narrowing. In man, Wright et al. (1969a) found no change after subtotal colectomy in the time taken for barium to reach the terminal ileum (average $180 \mathrm{~min}$ ), an observation compatible with ours in rats; Wright et al. also reported slight dilatation of the terminal ileum. The slow gastric emptying after right hemicolectomy in rats is not explained; a sinilar delay was noted by Nygaard (1967), but in his animals it occurred with small gut resection and anastomosis just beyond the duodenum.

GROWTH OF COLON AFTER HEMICOLECTOMY

The present results demonstrate growth in the colon downstream only from an excised portion. This is what occurs predominantly in the small intestine after partial excision of small intestine, though not exclusively; some upstream growth occurs (Dowling and Booth, 1967). A similar downstream effect was found by Nygaard (1967) who detected growth of the whole colon after massive ileal resection. The growth in our animals involved the mucosa more than the seromuscular coat, which again is the case in ileal growth after a jejunal resection (Dowling and Booth, 1967), and suggests increased absorptive function in the distal colonic remnant, since increased transport function evoked by dilution of the food with kaolin produces more growth of the colon's muscular coat (Dowling et al., 1967). The mechanisms responsible for the growth are not clear.

GROWTH OF SMALL INTESTINE AFTER COLECTOMY

The percentage increase in weight of the small intestine after subtotal colectomy corresponded to the percentage increase in food intake, and in the upper two-thirds was predominantly mucosal, with taller villi. These aspects are compatible with the view that increased luminal nutrition was an important factor (for references see Dowling, 1974). The lower third showed more seromuscular growth than the other two thirds, and a similar tendency is evident after right hemicolectomy (Fig. 6), though not reaching significance. This accords with the hypothesis that increased propulsive activity is required above an anastomosis between terminal ileum and colon, and hypertrophy of intestinal muscle ensues. The transit studies support this explanation.

The slight increase in enterocyte density at all levels may be discounted on the presumption that gut diameter was a little greater, which is possible since length changes were not found; as the total number of villi presumably does not change (Clarke, 1972; Forrester, 1972), a villus simply slightly stretched from side to side would show a little crowding of enterocytes up its height. The increase in villus height in the upper two-thirds of the small intestine clearly cannot be thus explained and is evidently real. On similar reasoning, the villi after right hemicolectomy might have shown some increase in height in the absence of stretching. Wright et al. (1969a,b) have demonstrated taller villi in the terminal ileum after subtotal colectomy in rat and man. Taller villi, with an increased number of enterocytes rather than enlargement of each 
enterocyte, is the condition in rat ileum after jejunal resection (Dowling and Booth, 1967).

Increased food intake, and increased propulsive work above an anastomosis between ileum and colon, may not wholly explain the growth changes found. First, right hemicolectomy led to growth of the small intestine, especially its lowest third, but not to increased food intake. Secondly, after subtotal colectomy pair feeding for three weeks did not entirely cancel the increase. It is possible that an even longer period of pair feeding might have done so, but pair feeding is open to the objection that the day's ration is taken rather rapidly, which in itself leads to intestinal growth (Fabry and Kujalova, 1960), although the effect during pair feeding should be slight (Brownlee and Moss, 1959). Gastrointestinal hormones may play an important part (for references see Barrowman, 1975). If so, the hormonal changes after colectomy do not require actual removal of the colon, since bypass alone is associated with small intestinal growth and increase in food intake indistinguishable from those after actual colectomy.

This work was done during the tenure of a WHO Fellowship by P. C. Masesa and the contribution of WHO to research expenses is gratefully acknowledged, as is the technical assistance of Mrs K. Grant and Mrs J. Anderson.

\section{References}

Barnes, R. H., Fiala, G., McGehee, B., and Brown, A. (1957). Prevention of coprophagy in the rat. Journal of Nutrition, 63, 489-498.

Barrowman, J. A. (1975). The trophic action of gastrointestinal hormones. Digestion, 12, 92-104.

Brownlee, A., and Moss, W. (1959). Changes in size of the gastrointestinal tract, liver and kidneys of the laboratory rat at different live weights and on different dietary regimes. British Veterinary Journal, 115, 225-234.

Clarke, R. M. (1972). The effect of growth and of fasting on the number of villi and crypts in the small intestine of the albino rat. Journal of Anatomy, 112, 27-33.

Dietschy, J. M. (1967). Effects of bile salts on intermediate metabolism of the intestinal mucosa. Federation Proceedings, 26, 1589-1598.
Dowling, R. H. (1968). Compensatory Mechanisms in the Small Intestine. Thesis: Queen's University of Belfast. (Quoted in Dowling (1974).)

Dowling, R. H. (1974). The influence of luminal nutrition on intestinal adaptation after small bowel resection and bypass. In Intestinal Adaptation, pp. 35-59. Edited by R. H. Dowling and E. O. Riecken. Schattauer: Stuttgart.

Dowling, R. H., and Booth, C. C. (1967). Structural and functional changes following small intestinal resection in the rat. Clinical Science, 32, 139-149.

Dowling, R. H., Riecken, E. O., Laws, J. W., and Booth, C. C. (1967). The intestinal response to high bulk feeding in the rat. Clinical Science, 32, 1-9.

Edholm, O. G., Fletcher, J. G., Widdowson, E. M., and McCance, R. A. (1955). The energy expenditure and food intake of individual men. British Journal of Nutrition, 9, 286-300.

Fabry, P., and Kujalova, V. (1960). Hypertrophie des Magens und des Dünndarmes der Ratte als Folgeerscheinung einer geanderter Zeiteinteilung der Nährungsaufnahme. Deutsche Zeitschrift für Verdauungs und Stoffwechselkrankheiten, 20, 295-299.

Forrester, J. M. (1972). The number of villi in rat's jejunum and ileum: effect of normal growth, partial enterectomy, and tube feeding. Journal of Anatomy, 111, 283-291.

Gleeson, M. H., Cullen, J., and Dowling, R. H. (1972). Intestinal structure and function after small bowel by-pass in the rat. Clinical Science, 43, 731-742.

Hall, R. J. C., and Creamer, B. (1974). Hyperphagia in intestinal disease. Gut, 15, 858-861.

Lambert, R. (1965). Surgery of the Digestive System in the Rat. Thomas: Springfield, Ill.

Masesa, P. C. (1975). Changes in Structure and Function of the Rat Alimentary Tract Following Removal of the Colon. Thesis: University of Edinburgh.

Masesa, P. C. (1976). Changes in the rat small intestine after subtotal colectomy. Journal of Physiology, 256, 47-48P.

Nygaard, K. (1967). Resection of the small intestine in rats. III. Morphological changes in the intestinal tract. Acta Chirurgica Scandinavica, 133, 233-248.

Southgate, D. A. T. (1973). Fibre and the other unavailable carbohydrates and their effects on the energy value of the diet. Proceedings of the Nutrition Society, 32, 131-136.

Wright, H. K., Cleveland, J. C., Tilson, M. D., and Herskovic, T. (1969a). Morphology and absorptive capacity of the ileum after ileostomy in man. American Journal of Surgery, 117, 242-245.

Wright, H. K., Poskitt, T., Cleveland, J. C., and Herskovic, T. (1969b). The effect of total colectomy on morphology and absorptive capacity of ileum in the rat. Journal of Surgical Research, 9, 301-304.

Yang, M. G., Manoharan, K., and Mickelsen, O. (1970). Nutritional contribution of volatile fatty acids from the cecum of rats. Journal of Nutrition, 100, 545-550.

Yang, M. G., Manoharan, K., and Young, A. K. (1969). Influence and degradation of dietary cellulose in the cecum of rats. Journal of Nutrition, 97, 260-264. 